\title{
Effect of friction welding conditions on tensile strength and hardness of AISI 310 stainless steel joints
}

\author{
Muhammad Iswar ${ }^{1, *}$ and Rusdi $\mathrm{Nur}^{2, *}$ \\ ${ }^{1}$ Mechanical Engineering Department, Politeknik Negeri Ujung Pandang, 90245 Makassar, Indonesia \\ ${ }^{2}$ Centre for Materials and Manufacturing, Politeknik Negeri Ujung Pandang, 90245 Makassar, \\ Indonesia
}

\begin{abstract}
This study aims to determine the effect of rotational speed and forging time on tensile strength and hardness through the friction welding process of stainless steel AISI 310. The research was carried out by friction welding process by using the lathe machine with varying rotational speed (550, 1020 and $1800 \mathrm{rpm})$, forging time $(25,35,45$ seconds), and welding temperature of $1050^{\circ} \mathrm{C} \pm 10^{\circ}$. Axial pressure was obtained through the addition of a hydraulic system to the release head of a lathe machine with a forging pressure of $123.8 \mathrm{~N} / \mathrm{mm}^{2}$. Furthermore, the friction welding results were tested mechanically by conducting the tensile and hardness tests. The experimental results showed that the highest tensile strength of the friction welding result of $706,61 \mathrm{~N} / \mathrm{mm}^{2}$ was obtained at $1800 \mathrm{rpm}$ and 45 seconds, and this value is lower when compared with raw material $(780,25$ $\left.\mathrm{N} / \mathrm{mm}^{2}\right)$. The highest hardness value (61.5 HRC-A) was located on the welded joint section with $550 \mathrm{rpm}$ of rotational speed and 25 seconds of forging time. The hardness of the parent metal is 69.45 HRC-A. The rotational variation influences the hardness value, the higher the rotational speed will increase the hardness. The longer of forging time will decrease the hardness.
\end{abstract}

\section{Introduction}

Welding is one of the metal grafting techniques by liquefying some parent metal and filler metal with or without pressure and with or without additional metal and producing continuous connection. Generally, the technique of welding metal is divided into three methods, i.e. fusion welding, solid state welding and soldering and brazing. Friction welding is a type of solid state welding.

Friction welding is used extensively in various industries. Heat in friction welding is generated by conversion of mechanical energy into thermal energy at the interface of work pieces during rotational under pressure. Various ferrous and non-ferrous alloys having circular or non-circular cross sections and having different thermal and mechanical properties can easily be joined by friction welding method. Friction welding is a process

* Corresponding author: rusdinur@poliupg.ac.id 
where metallic bonding is produced at temperatures lower than the melting point of the base metals. Friction time, friction pressure, forging time, forging pressure and rotational speed are the most important parameters in the friction welding method [1].

In practice, friction welding is classified in two ways; continuous drive friction welding and inertia friction welding $[2,3]$. In the continuous drive friction method (Figure 1), one of the components is held stationary while the other is rotated at a constant speed (s). The two components are brought together under axial pressure $\left(\mathrm{P}_{\mathrm{f}}\right)$ for a certain friction time $\left(\mathrm{t}_{\mathrm{f}}\right)$. Then, the clutch is separated from the drive, and the rotary component is brought to stop within the braking time while the axial pressure on the stationary part is increased to a higher upset pressure $\left(\mathrm{P}_{\mathrm{u}}\right)$ for a predetermined upset time $\left(\mathrm{t}_{\mathrm{u}}\right)$. Conditions of the method are shown in Figure 2.

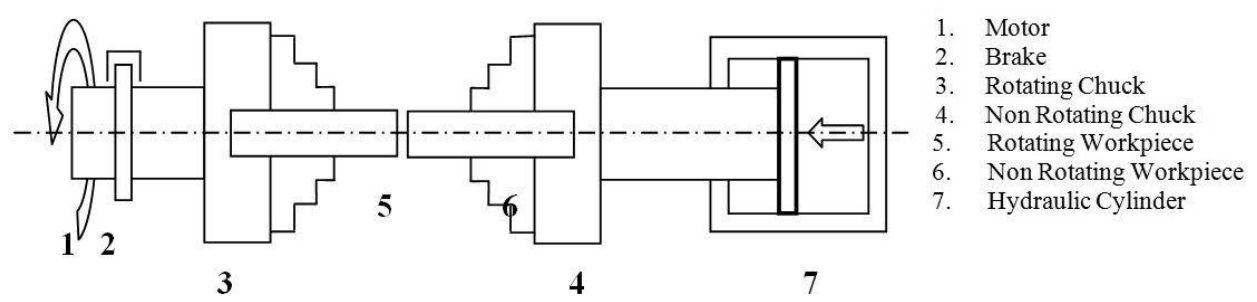

Fig. 1. Schematic of continuous drive friction welding [4].

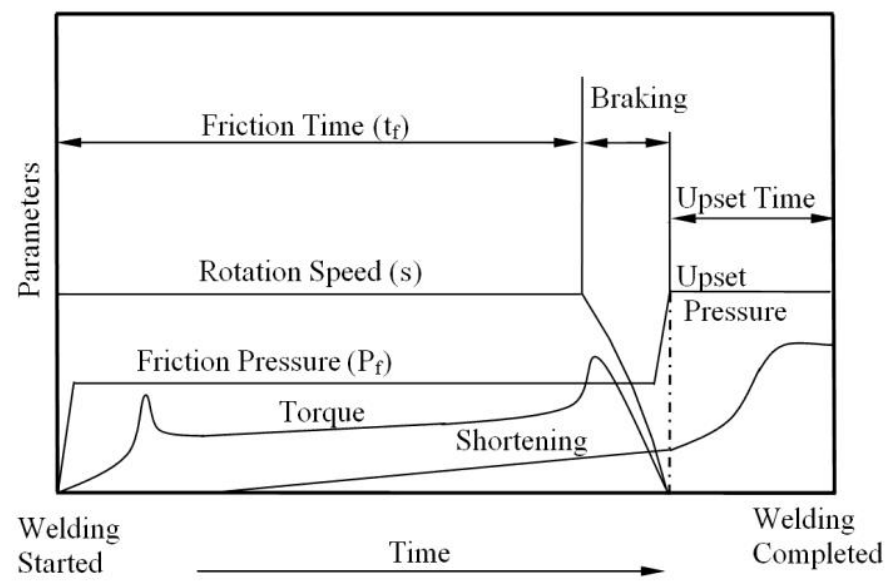

Fig. 2. Conditions for continuous friction welding [4].

In the friction welding method, the second component is held stationary for welding, while one of the components is clamped in a spindle chuck, usually with attached fly wheels. The fly wheel and chuck assembly is rotated at a certain speed (s) to store a predetermined amount of energy. Then, the drive to the flywheel is declutched, and the two components are brought together under axial pressure (Pf) for welding. Friction between the parts decelerates the flywheel converting stored energy to frictional heat. The process of metal grafting that occurs due to friction due to rotational of metal one to another under the influence of axial pressure. The basic steps of the friction welding process are shown in the Figure 3. 


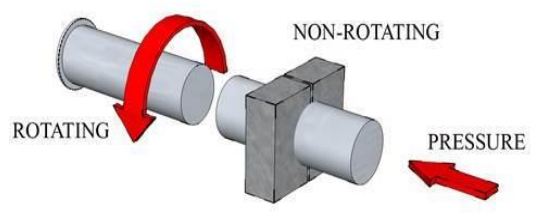

Step 1

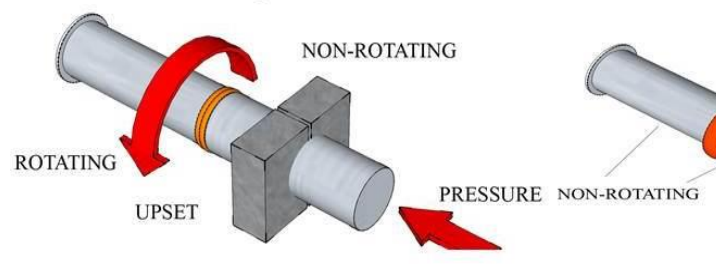

Step 3

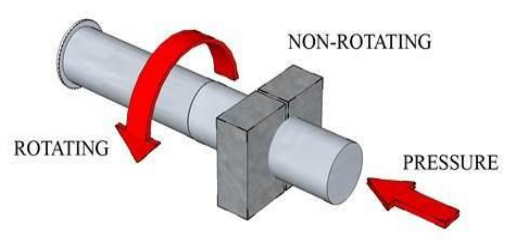

Step 2

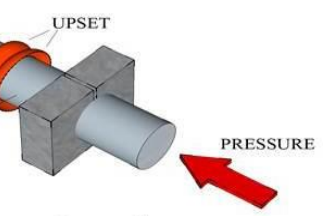

Step 4

Fig. 3. Steps in friction welding [5].

\section{Experimental Schematic}

\subsection{Material}

In the experiments, AISI 301 austenitic-stainless steel was used. The chemical composition of AISI 310 stainless steel is given in Table 1.

Table 1. Composition ranges for AISI 310 stainless steel.

\begin{tabular}{|c|c|c|c|c|c|c|c|c|}
\hline Grade & $\mathbf{C}$ & $\mathbf{M n}$ & $\mathbf{S i}$ & $\mathbf{P}$ & $\mathbf{S}$ & $\mathbf{C r}$ & $\mathbf{N i}$ & $\mathbf{N}$ \\
\hline Min & - & - & - & - & - & - & 6.0 & - \\
\hline Max. & 0.15 & 2.0 & 1.0 & 0.045 & 0.030 & 18.0 & 8.0 & 0.10 \\
\hline
\end{tabular}

\subsection{Equipment and Machining Parameters}

The equipment used is a lathe machine (Pindad) modified by the addition of hydraulic system to be done for the friction welding process. The lathe machine for experiment has been using for turning of stainless steel [5-6]. Other equipments as measuring instrument are infrared thermometer, stopwatch, ultimate tensile machine (UTM Galdabini), and hardness testing machine (Affri MX 206) with Harness Rockwell Cone method.

The parameters for friction welding process used were shown in Table 2.

Table 2. The parameters of friction welding experiments.

\begin{tabular}{|l|l|}
\hline \multicolumn{1}{|c|}{ Item } & \multicolumn{1}{c|}{ Parameters } \\
\hline Rotational speed (rpm) & $550,1020,1800$ \\
\hline Forging time (s) & $25,35,45$ \\
\hline Friction pressure, $\mathrm{P}_{\mathrm{f}}(\mathrm{MPa})$ & 82.1 (constant) \\
\hline
\end{tabular}




\subsection{Experimental Setup}

An experimental set-up was designed and constructed as a continuous drive type (Figure 4).

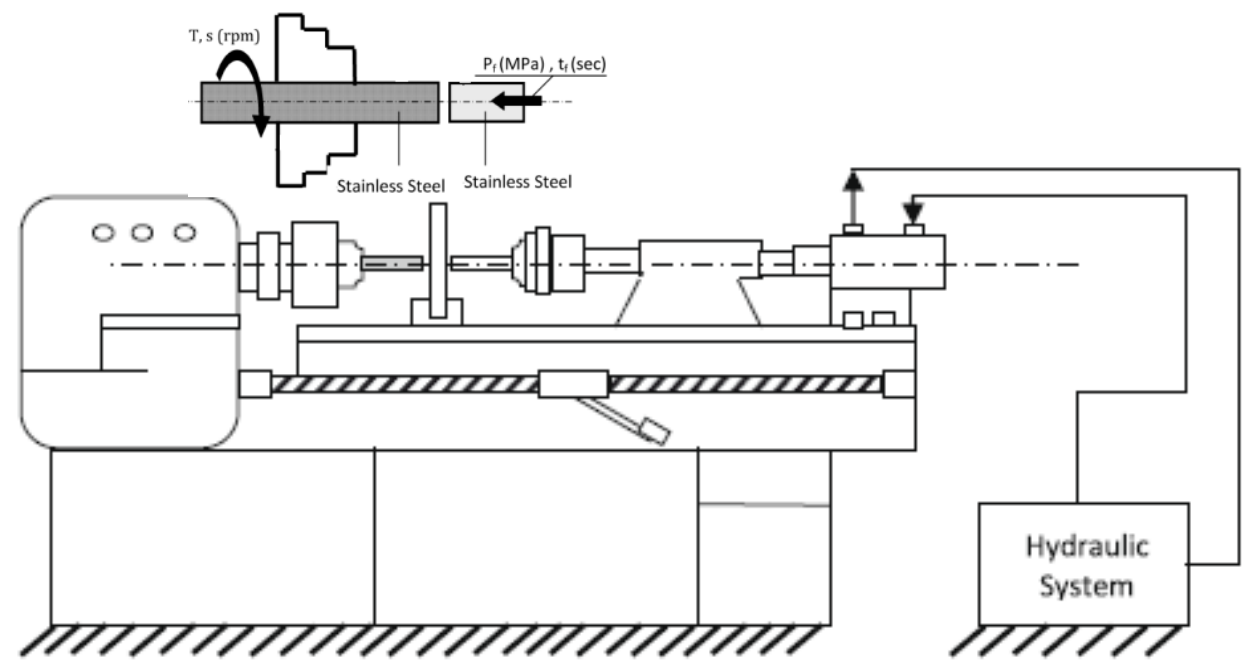

Fig. 4. Schematic diagram for welding friction.

\section{Results and discussion}

\subsection{Tensile Strength}

The tensile testing was performed using a Galdabini Universal Testing Machine with 10 ton capacity. The type specimen for tensile strength have size according to ISO 82-1974 (E), DP8, $l o=80 \mathrm{~mm}$, as shown in Figure 5 .

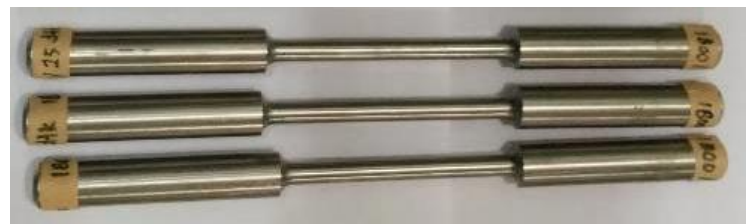

Fig. 5. Specimen for the tensile test.

The data of tensile test is obtain and show in Figure 6. The result analysis of tensile test shows that the highest maximum tensile strength is $706,61 \mathrm{~N} / \mathrm{mm}^{2}$ with strain of $7.72 \%$ at $1800 \mathrm{rpm}$ of rotational parameter and 45 seconds of forging time. While the lowest strength of $477,7 \mathrm{~N} / \mathrm{mm}^{2}$ with a strain of $1.8 \%$ was obtained at $550 \mathrm{rpm}$ and 25 seconds of forging time. Tensile strength is not sensitive to changes in rotational speed and forging time.

The specimen form was generated through the friction welding process has joined the AISI 301 pipeline with a solidity rate of $97 \%$, as shown in Figure 7. Sathiya et al [7] presented that the tensile specimen failures were associated primarily with the weld interface region. The tensile test was performed by Dey et al. [8], it concluded that post-weld heat treatment (PWHT) has marginal effect on improving the bend ductility of the joints. Bhamji et al. [9] found that mechanically sound linear friction welds could be produced in $316 \mathrm{~L}$, with tensile properties in most welds exceeding those of the parent material. Also their experiment [9], they investigated the effect of welding parameters through friction stir welding of AA5052. 

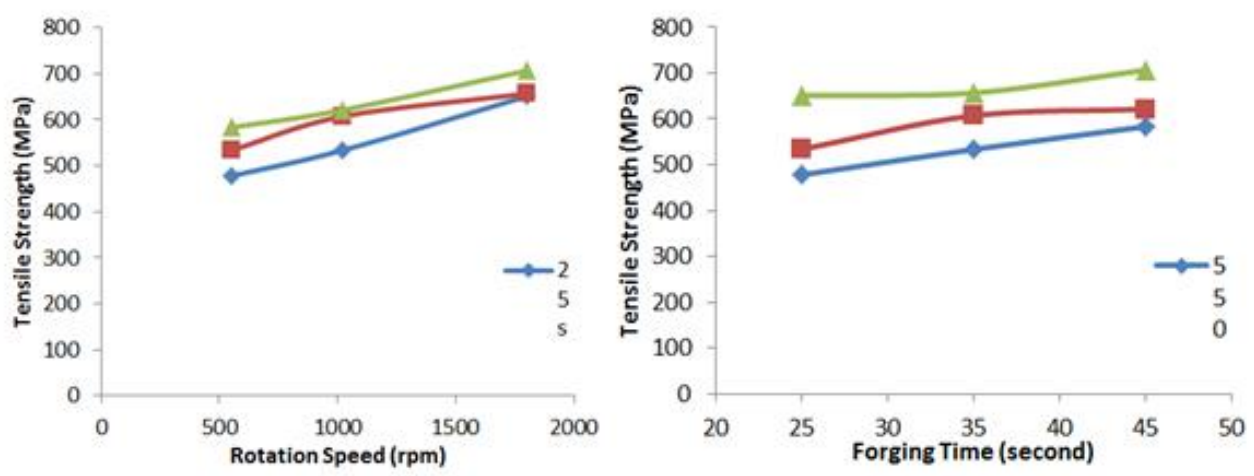

Fig. 6. Data of tensile strength for difference of rotational speeds and forging time.

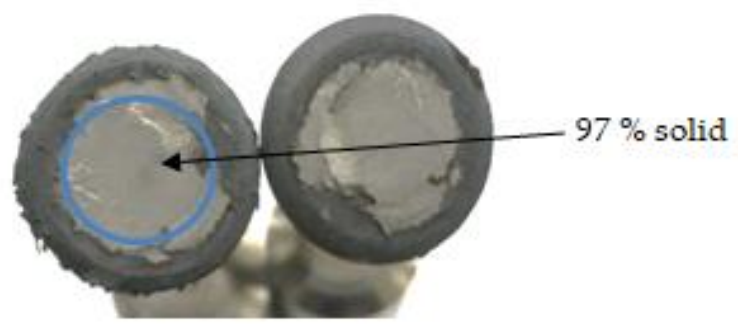

Fig. 7. The shape of specimen after tensile test.

\subsection{Hardness}

Hardness testing using the rockwell cone (HRC) method with pyramidal diamonds with $120^{\circ}$ of peak angles loaded. Rockwell's hardness testing is based on the depth of emphasis on the material under test. The area tested for hardness was separated in the weld area (1 point), heat affected area (HAZ) (4 points), and the parent metal (2 points), which is shown in Figure 8.

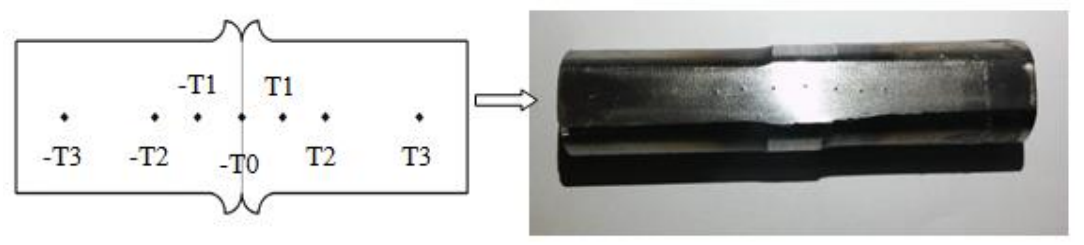

Fig. 8. The position for hardness test.

The result of hardness test is obtain and show in Figure 9. In the welded joint area and HAZ, the hardness value will decrease with the longer forging time. Hardness values will increase for lower temperatures at rotational speed conditions of $1020 \mathrm{rpm}$ and $1800 \mathrm{rpm}$. However, the hardness value is higher at $1800 \mathrm{rpm}$ of rotational speed and 45 seconds of forging time. The difference in hardness values on welded joints is not very large, ranging from 1-8 HRC-A. Dey et al [8] presented that micro-hardness profile confirmed the occurrence of strain hardening of Ti near the joint interface in the as-welded condition and reduction in the effects of strain hardening by PWHT. 

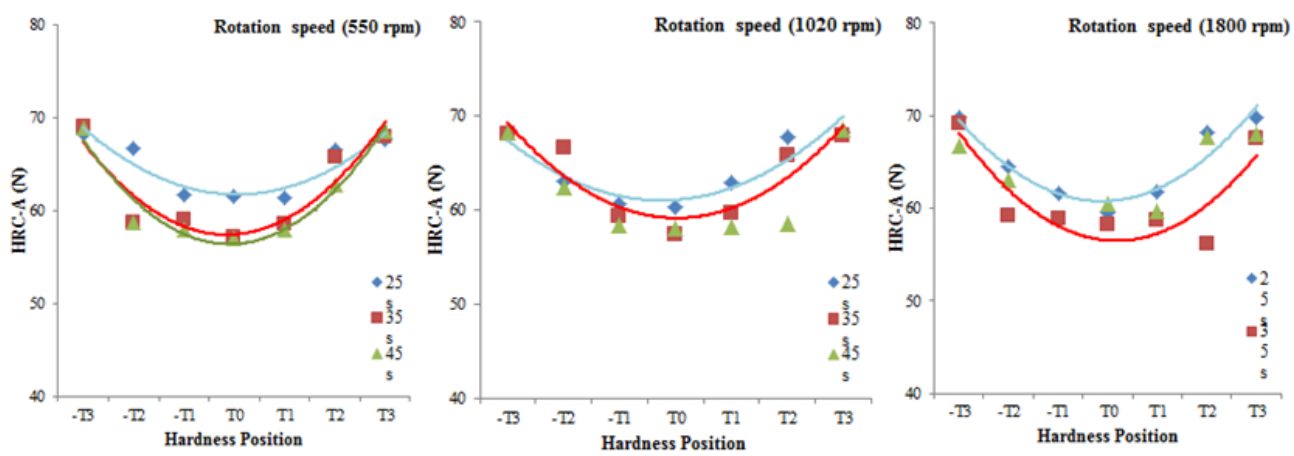

Fig. 9. Data of hardness for difference of rotational speeds.

\section{Conclusion}

Based on the results of data analysis, it can be concluded as follows:

1. The tensile strength increases for higher of rotational speed and also for the longer of forging time. The tensile strength of welding results are almost equal to the raw material.

2. In the welded joints, HAZ has lower hardness compared to the parent metal. The lower temperature is obtain at the higher of hardness value. The rotational speed influences the hardness, the higher of rotational speed will be make the hardness increases.

\section{References}

1. V. I. Vill, Fric. Weld. of Met. AWS New York (1962)

2. M. Sahin and C. Misirli. InTech. (2012)

3. W. Kinley, Weld. \& Met. Fabri. Oct 585-589 (1971)

4. N. I. Fomichev, Weld. Prod. 3538 (1980)

5. R. Nur, M.Y. Noordin, I. Sudin, and D. Kurniawan, Proceed. Inst. Mech. Eng. Part E: J. Pro. Mech. Eng. 231 (4), 676-683 (2017)

6. R. Nur, ARPN J. Eng. Appl. Sci. 12 (6), 1885-1889 (2017)

7. P. Sathiya, Aravindan, S. and Haq, A.N., The Int. J. of Adv. Manuf. Tech., 31(11-12) 1076-1082. (2007)

8. Dey, H.C., Ashfaq, M., Bhaduri, A.K. and Rao, K.P., J of Mater Proc. Tech., 209 (1819) 5862-5870. (2009)

9. I. Bhamji, M. Preuss, P.L. Threadgill, R.J. Moat, A.C. Addison, and M.J. Peel, Mater. Sci. and Eng.: A, 528 (2) 680-690 (2010)

10. R. Nur, M.A. Suyuti and A.Z. Sultan, ARPN J. Eng. Appl. Sci. 12 (16), 4445-4450 (2017) 